\title{
COMPARISON OF LICHTENSTEIN'S TENSION FREE MESH REPAIR WITH GPRVS-STOPPA'S REPAIR FOR BILATERAL INGUINAL HERNIA
}

\author{
Abdul Latheef $A^{1}$, R. V. Ramlal2, Ansar P3 \\ 1 Professor and HOD, Department of Surgery, TD Medical College, Alappuzha. \\ ${ }^{2}$ Associate Professor, Department of Surgery, TD Medical College, Alappuzha. \\ ${ }^{3}$ Senior Resident, Department of Surgery, TD Medical College, Alappuzha.
}

\section{ABSTRACT}

\section{BACKGROUND}

Inguinal hernia is one of the most common surgical problem that presents to a surgeon in his outpatient department. The aim of this study is to compare the early and long-term health status and clinical outcomes of Stoppa and bilateral Lichtenstein hernia repair.

\section{MATERIALS AND METHODS}

The Stoppa group consisted of 24 patients and Lichtenstein's group consisted of 26 patients. Both groups were similar with respect to age, gender and post-operative followup. All the patients were followed up for a period of one year and compared the parameters like operating time, early complications, chronic groin pain and early recurrence.

\section{RESULTS}

Operating time, early post-operative complications and chronic groin pain were comparable in both groups except for recurrent hernia, in which operative time taken for Lichtenstein repair is slightly more. Time for post-operative recovery to normal activities is less in Lichtenstein group and time taken for resumption of work is less in Stoppa group.

\section{CONCLUSION}

Giant prosthetic reinforcement of the visceral sac-Stoppa's repair is a good alternative to Lichtenstein repair for primary bilateral hernia and is superior for recurrent hernia.

\section{KEYWORDS}

Lichtenstein Repair, Stoppa Repair, Postoperative Recovery.

HOW TO CITE THIS ARTICLE: Latheef AA, Ramlal RV, Ansar P. Comparison of Lichtenstein's tension free mesh repair with GPRVSStoppa's repair for bilateral inguinal hernia. J. Evolution Med. Dent. Sci. 2017;6(26):2164-2168, DOI: 10.14260/Jemds/2017/469

\section{BACKGROUND}

Inguinal hernia is one of the most common surgical problem that presents to a surgeon in his outpatient department, making hernia repair one of the most common operations performed by general surgeons. Hernia repair is one of the cornerstones of a general surgery practice.

\section{Hernia}

The word "Hernia" is derived from the Latin word for rupture. A hernia ${ }^{1,2}$ is defined as a protrusion of a viscus or a part of viscus through an abnormal opening in the walls of its containing cavity. ${ }^{3}$

Since the mid 1980's dramatic progress has been made in the evolution of hernia surgery, $4,5,6$ by the increasing use of prosthetic mesh. There are various methods in the placement of prosthetic mesh in hernioplasty. ${ }^{7}$

The concept of avoiding tension by onlay mesh repair was championed by Lichtenstein. Lichtenstein theorised that by using a mesh prosthesis to bridge the hernia defect rather

Financial or Other, Competing Interest: None.

Submission 23-02-2016, Peer Review 19-03-2017,

Acceptance 25-03-2017, Published 30-03-2017.

Corresponding Author:

Dr. Abdul Latheef $A$

Professor and HOD,

Department of Surgery,

TD Medical College,

Alapuzha.

E-mail: drlatheef62@gmail.com

DOI: $10.14260 /$ jemds $/ 2017 / 469$

\section{(c) $(1) \ominus$}

than closing it with sutures tension is avoided, ostensibly resulting in a less painful operation. Now Lichtenstein's tension free mesh repair ${ }^{8}$ is considered as Gold standard for hernia surgery.

The preperitoneal space ${ }^{9,10}$ can also be used for repair of an inguinal hernia, because of the mechanical advantage gained from prosthesis placement behind the abdominal wall. Giant Prosthetic Reinforcement of the Visceral Sac is one of the technique in the field of hernia surgery introduced by Stoppa RE in 1989. In this innovative technique, Stoppa used polyester Dacron for bilateral preperitoneal prosthetic hernia repair.

In this study, I have used prosthetic mesh of prolene for the repair of bilateral inguinal hernia by Stoppa's technique and have compared the morbidity and results of various Lichtenstein's repair with that of Stoppa's technique.

\section{Aim of Study}

To compare the advantages and disadvantages of GPRVSStoppa's hernia repair with Lichtenstein's repair for bilateral hernia, which includes-

- Operating time.

- Postoperative complications.

- Duration of hospital stay.

- Days taken to return to normal activity.

- Days taken to return for work.

- Early recurrence.

- Chronic groin pain. 


\section{Methodology}

Study Design

Comparative observational study.

\section{Duration of Study}

12 Months (February 2014 to February 2015).

\section{Sample Size}

The average number of patients being admitted in one surgical unit for elective bilateral hernia repair per year was fifty. Hence, the sample size was selected as fifty.

\section{Inclusion Criteria}

1. Patients admitted in the Department of General Surgery in Govt. T.D. Medical College Hospital diagnosed to have bilateral inguinal hernia giving consent to participate in the study were included.

2. Patients admitted with recurrent inguinal hernia following surgical repair.

\section{Exclusion Criteria}

1. Irreducible or obstructed hernia.

2. Congenital inguinal hernia.

\section{Study Procedure}

All patients who presented with uncomplicated bilateral direct inguinal hernia were included in the study. Patients are allocated to two groups. Patients were allocated to two groups randomly; patients admitted on Wednesday were allocated to the Stoppa group and patients admitted on Fridays were allocated to the Lichtenstein's group. The inclusion into the study was done after explaining the purpose and procedure of the study and after obtaining informed consent from the patients. The two groups of patients were comparable in age, body weight index, comorbidities, size and type of hernia. Informed consent was obtained from patients.

Preoperative investigations include $\mathrm{Hb}, \mathrm{TC}, \mathrm{DC}$, platelet count, ESR, chest and abdomen x-ray, RBS, S. Electrolytes, ECG, viral markers.

All patients are empirically started on broad-spectrum antibiotic cefotaxime $1 \mathrm{gm}$ at induction of anaesthesia followed by definitive surgery either Lichtenstein or GPRVSStoppa's hernia repair. Mesh used in both methods of repair is polypropylene mesh. Due to non-availability of Dacron mesh in our centre, we have used prolene mesh for repair.

Operating time for primary hernia and recurrent hernia was compared in this study. During post-operative period the incidence of haematoma, wound infection, sinus formations and rejection of mesh were compared in both groups of patients.

Duration of hospital stay, days taken for return to normal activity and return to work were also compared in each group. In all cases on review, we have examined for early recurrence of hernia formation.

Statistical methods and analysis.

Data was consolidated and organised into graphs and tables using Microsoft Excel.

Qualitative variables were compared using Chi square test and Fisher exact test.

Quantitative variables were compared using unpaired ttest.
Observation and Analysis

Total number of cases studied- 50 .

26 cases underwent Lichtenstein's Hernia repair.

24 cases underwent GPRVS repair.

All were males.

\begin{tabular}{|c|c|c|}
\hline & N & \% \\
\hline Lichtenstein & 26 & 52 \\
\hline GPRVS & 24 & 48 \\
\hline Total & $\mathbf{5 0}$ & $\mathbf{1 0 0}$ \\
\hline \multicolumn{2}{|c|}{ Table 1. Total Number of Cases } \\
\hline
\end{tabular}

\begin{tabular}{|c|c|c|c|c|}
\hline $\begin{array}{c}\text { Types of } \\
\text { Surgery }\end{array}$ & $\begin{array}{c}\text { Mean Operating } \\
\text { Time (Minutes) }\end{array}$ & SD & T-value & P-value \\
\hline Lichtenstein & 103.1 & 7.4 & \multirow{2}{*}{1.448} & 0.1540 \\
\hline GPRVS & 99.8 & 8.7 & & \\
\hline \multicolumn{4}{|c|}{ Table 2. Operating Time } \\
\hline
\end{tabular}

\begin{tabular}{|c|c|}
\hline Types of Surgery & Mean Operating Time (Minutes) \\
\hline Lichtenstein & 125.4 \\
\hline GPRVS & 104.4 \\
\hline \multicolumn{2}{|c|}{ Table 3. Operating Time for Recurrent Hernia } \\
\hline
\end{tabular}

\begin{tabular}{|c|c|c|c|c|c|c|}
\hline \multirow{2}{*}{ Haematoma } & \multicolumn{2}{|c|}{ Lichtenstein } & \multicolumn{2}{c|}{ GPRVS } & \multicolumn{2}{c|}{ Total } \\
\cline { 2 - 7 } & $\mathbf{N}$ & $\mathbf{\%}$ & $\mathbf{N}$ & $\mathbf{\%}$ & $\mathbf{N}$ & $\mathbf{\%}$ \\
\hline Yes & 5 & 19.2 & 2 & 8.3 & 7 & 14 \\
\hline No & 21 & 80.8 & 22 & 91.7 & 43 & 86 \\
\hline Total & 26 & 100 & 24 & 100 & 50 & 100 \\
\hline \multicolumn{6}{|c|}{ Table 4. Haematoma } \\
\hline
\end{tabular}

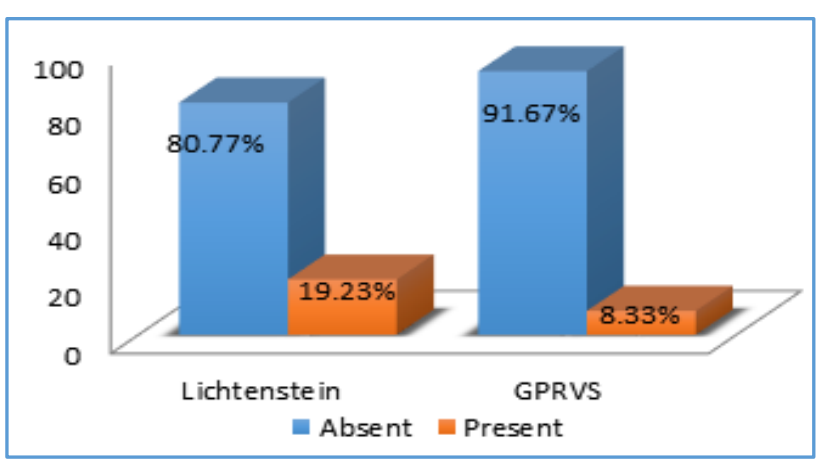

Figure 1. Haematoma

With Lichtenstein 5/26 (19.23\%) developed haematoma, whereas only $2 / 24$ (8.33\%) developed haematoma in GPRVS group. ( $\mathrm{P}>0.005$ using Fisher Exact statistic).

\section{Immediate Postoperative Pain}

- Scoring of postoperative pain.

- Numerical scale.

- 0 - no pain.

- 10- Maximum possible pain.

- Severe pain is defined as score of more than five.

- Mean visual analogue scale pain in Lichtenstein is 3.74 .

- Mean visual analogue scale pain in GPRVS is 4.79. 


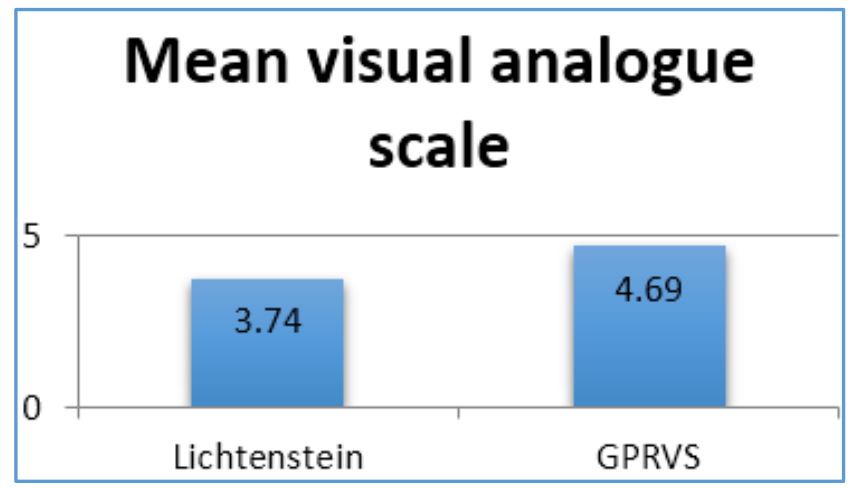

Figure 2. Immediate Postoperative Pain

There is no statistically significant difference in immediate postoperative pain.

\begin{tabular}{|c|c|c|c|c|c|c|}
\hline \multirow{2}{*}{ SSI } & \multicolumn{2}{|c|}{ GPRVS } & \multicolumn{2}{c|}{ Lichtenstein } & \multicolumn{2}{c|}{ Total } \\
\cline { 2 - 7 } & $\mathbf{N}$ & $\mathbf{\%}$ & $\mathbf{N}$ & $\mathbf{\%}$ & $\mathbf{N}$ & $\mathbf{\%}$ \\
\hline Yes & 0 & 0 & 2 & 7.7 & 2 & 4.1 \\
\hline No & 24 & 100 & 24 & 92.3 & 48 & 95.9 \\
\hline Total & $\mathbf{2 4}$ & $\mathbf{1 0 0}$ & $\mathbf{2 6}$ & $\mathbf{1 0 0}$ & $\mathbf{5 0}$ & $\mathbf{1 0 0}$ \\
\hline \multicolumn{6}{|c|}{ Table 5. Surgical Site Infection } \\
\hline
\end{tabular}

$x^{2}=1.845, d f=1, p=0.174$

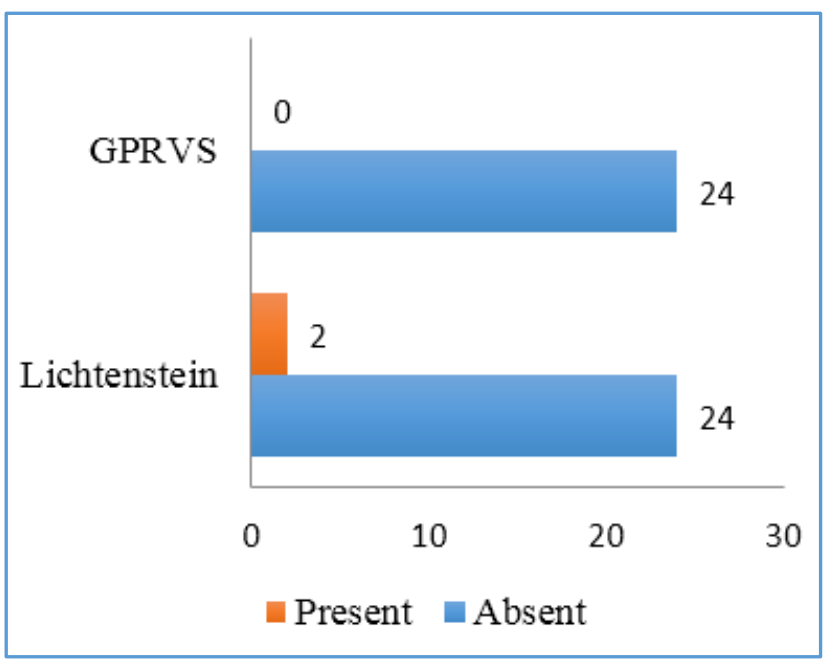

Figure 3. Surgical Site Infection

P- value $>0.05$

No statistically significant difference in incidence of surgical site infection in either groups.

\section{Rejection of Mesh}

None of the cases developed rejection of mesh with either Lichtenstein or GPRVS technique.

\section{Chronic Groin Pain}

Chronic groin pain is that pain, which lasts for more than 3 months.

Or

That pain which lasts for more than 1 month after the usual time that is required for an insult to heal.

\begin{tabular}{|c|c|c|c|c|c|c|}
\hline \multirow{2}{*}{ Chronic Pain } & \multicolumn{2}{|c|}{ GPRVS } & \multicolumn{2}{c|}{ Lichtenstein } & \multicolumn{2}{c|}{ Total } \\
\cline { 2 - 7 } & $\mathbf{N}$ & $\mathbf{\%}$ & $\mathbf{N}$ & $\mathbf{\%}$ & $\mathbf{N}$ & $\mathbf{\%}$ \\
\hline YES & 0 & 0 & 3 & 11.5 & 3 & 6.1 \\
\hline NO & 24 & 100 & 23 & 88.5 & 47 & 93.9 \\
\hline TOTAL & 24 & 100 & 26 & 100 & 50 & 100 \\
\hline \multicolumn{3}{|c|}{ Table 6. Chronic Groin Pain } \\
\hline
\end{tabular}

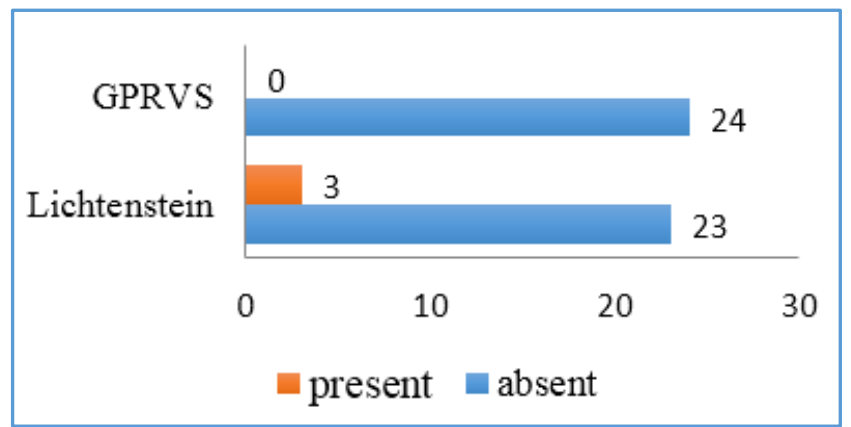

\section{Figure 4. Chronic Groin Pain}

$\mathrm{P}>0.05$

This difference was found to be statistically insignificant.

\section{Early Recurrence}

None of the cases developed early recurrence with GPRVS technique, whereas with Lichtenstein technique one patient developed recurrence. (P-value $>0.05$ ).

\begin{tabular}{|c|c|c|c|c|c|c|}
\hline \multirow{2}{*}{ Recurrence } & \multicolumn{2}{|c|}{ GPRVS } & \multicolumn{2}{c|}{ Lichtenstein } & \multicolumn{2}{c|}{ Total } \\
\cline { 2 - 7 } & $\mathbf{N}$ & $\mathbf{\%}$ & $\mathbf{N}$ & $\mathbf{\%}$ & $\mathbf{N}$ & $\mathbf{\%}$ \\
\hline Yes & 0 & 0 & 1 & 3.8 & 1 & 2 \\
\hline No & 24 & 100 & 25 & 96.2 & 49 & 98 \\
\hline Total & $\mathbf{2 4}$ & $\mathbf{1 0 0}$ & $\mathbf{2 6}$ & $\mathbf{1 0 0}$ & $\mathbf{5 0}$ & $\mathbf{1 0 0}$ \\
\hline \multicolumn{6}{|c|}{ Table 7. Early Recurrence } \\
\hline
\end{tabular}

$\mathrm{x}^{2}=1.154, \mathrm{df}=1, \mathrm{p}=0.283$

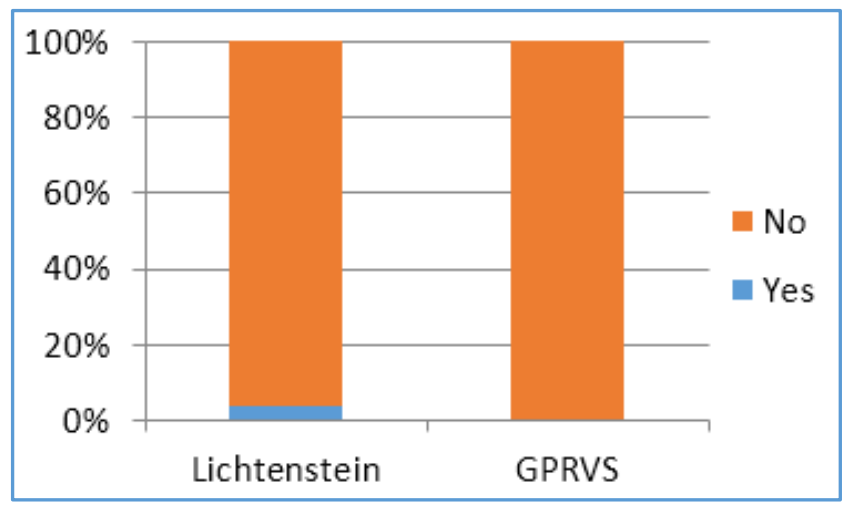

Figure 5. Early Recurrence

\begin{tabular}{|c|c|c|c|c|}
\hline $\begin{array}{c}\text { Types of } \\
\text { Surgery }\end{array}$ & $\begin{array}{c}\text { Mean Duration of } \\
\text { Hospital Stay }\end{array}$ & SD & T-value & P-value \\
\cline { 1 - 4 } Lichtenstein & 5.78 & 6 & 0.6850 & 0.4967 \\
\cline { 1 - 3 } GPRVS & 7.04 & 7 & & \\
\cline { 1 - 2 } & \multicolumn{3}{|c|}{ Table 8. Duration of Hospital Stay } \\
\hline
\end{tabular}




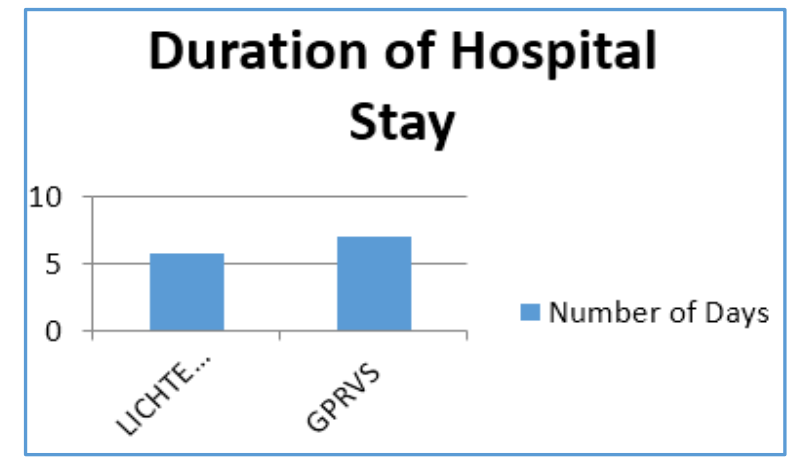

Figure 6. Duration of Hospital Stay

There is no statistically significant difference in hospital stay in both groups.

\begin{tabular}{|c|c|c|c|}
\hline $\begin{array}{c}\text { Types of } \\
\text { Surgery }\end{array}$ & $\begin{array}{c}\text { Number of Days taken for } \\
\text { Return to Normal Activity }\end{array}$ & $\begin{array}{c}\text { T- } \\
\text { value }\end{array}$ & $\begin{array}{c}\text { P- } \\
\text { value }\end{array}$ \\
\hline Lichtenstein & 9 & 3.015 & 0.0041 \\
\hline GPRVS & 12 & \\
\hline \multicolumn{3}{|c|}{$\begin{array}{c}\text { Table 9. Number of Days taken for Return to } \\
\text { Normal Activity }\end{array}$} \\
\hline
\end{tabular}

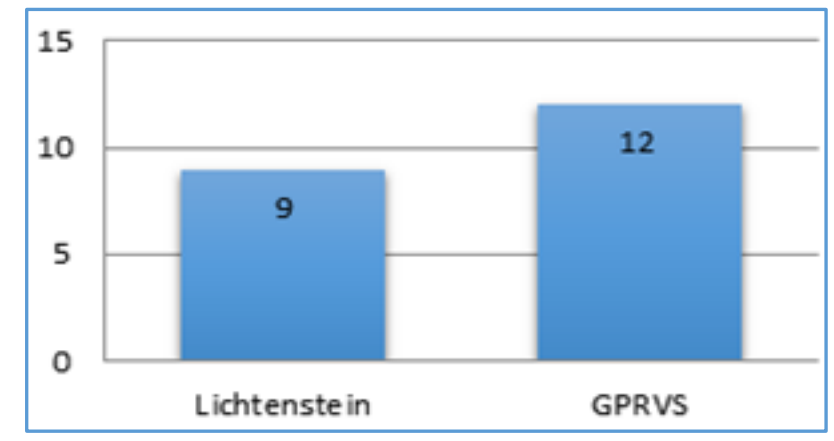

Figure 7. Number of Days taken for Return to Normal Activity

T- value: 3.015 ; P-value: 0.0041

There is statistically significant difference in number of days taken for return to normal activity between the two groups. GPRVS took more days for returning to normal activity compared to Lichtenstein hernia repair.

\begin{tabular}{|c|c|c|c|}
\hline $\begin{array}{l}\text { Types of } \\
\text { Surgery }\end{array}$ & $\begin{array}{l}\text { Number of Days } \\
\text { taken for Work }\end{array}$ & T-value & P-value \\
\hline Lichtenstein & 42 & \multirow{2}{*}{3.532} & \multirow{2}{*}{0.0009} \\
\hline GPRVS & 38 & & \\
\hline
\end{tabular}

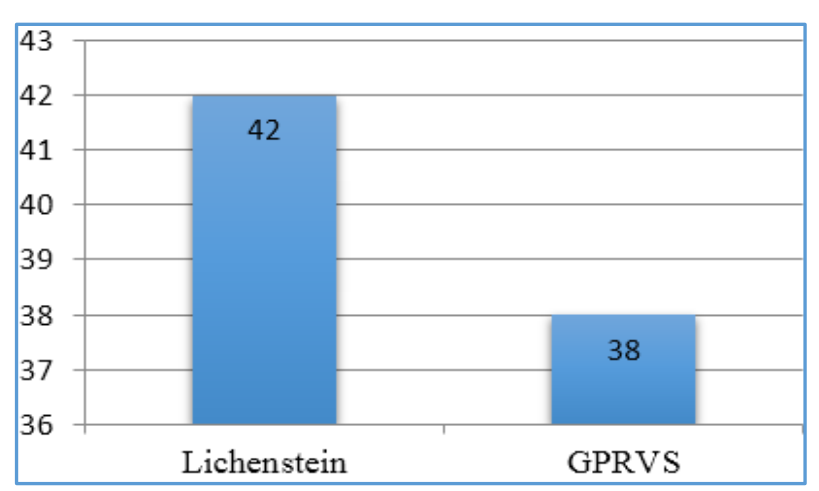

Figure 8. Number of Days taken for Work
T- value: 3.532; P-value: 0.0009 .

There is statistically significant difference in number of days taken for return to work between the two groups. Lichtenstein took more days for returning to work compared to GPRVS hernia repair.

\section{Statistical Analysis}

In analysing the variables, Chi-Square test was used. A Pvalue of less than 0.05 will be considered to be statistically significant and a $\mathrm{P}$ value of more than 0.05 will not be found to be statistically significant.

\section{DISCUSSION}

The present study was designed primarily to provide an answer to the question of whether preperitoneal prosthetic placement is better tolerated in bilateral inguinal hernia than subaponeurotic positioning. Secondary end points were other early and late complications; there was no statistically significant difference between two study groups in terms of demographic or type of hernia.

Out of the total 50, 26 patients underwent Lichtenstein repair and 24 patients underwent GPRVS repair. All the patients were males. Average age of patients were 53.7 in GPRVS series and 58.9 in Lichtenstein series.

Even though Stoppa introduced the giant prosthetic reinforcement of visceral sac with polyester Dacron mesh, we used prolene mesh for GPRVS repair because of nonavailability of Dacron mesh in our centre. The prolene mesh of correct shape and size was placed in preperitoneal space.

The average duration of illness were 1.8 years in GPRVS and 2 years in Lichtenstein. Both groups are comparable on duration of illness; 18 patients in Lichtenstein group were smokers and 15 patients in GPRVS group were smokers. The relationship between smoking and hernia formation as well as recurrence was first reported in 1981 and further research has identified proteolytic enzymes that may degrade the connective tissue components. In our study the average time for surgery was comparable in both groups, but in recurrent inguinal hernia GPRVS duration of operating time, postoperative complications and recurrence rate were significantly less as compared to Lichtenstein repair.

There were 2 haematomas in GPRVS and 5 in Lichtenstein hernia repair. All haematomas were managed conservatively. The higher incidence in Lichtenstein may be due to increased dissection and mesh fixing sutures in the more vascular subaponeurotic plane compared to relatively avascular preperitoneal space. No statistically significant difference between immediate postoperative pain in two groups. The increased immediate postoperative pain in Lichtenstein group can be attributed to more dissection and sutures in the subaponeurotic neurovascular plane. There were no serious surgical site infection in either group, which required removal of mesh.

There were 3 cases of chronic groin pain reported in Lichtenstein group compared to none in GPRVS. This difference was found to be statistically insignificant. Increased incidence of chronic groin pain in Lichtenstein group may be due to the increased dissection in subaponeurotic neurovascular plane and also due to constant contact and impingement of the nerves with the mesh. The ilioinguinal and the iliohypogastric nerves are generally injured during the elevation of the external oblique fascial 
flaps for fixation of mesh, while the genitofemoral nerve is most likely to be injured during the isolation of the cord and stripping of the cremasteric muscle fibres in Lichtenstein repair. While taking the bites for fixing the polypropylene mesh, the nerves may be injured accounting for the increased incidence of inguinal pain.

There is no obvious difference in recurrence rates and there was no significant difference in duration of hospital days, but number of days taken to return to normal activities is more for Stoppa's repair and for return to previous work is more for Lichtenstein repair. Thus, the present study along with previous data indicates that there is no just one right way to cure inguinal herniation. At present time, both deep and superficial prosthetic placements are satisfactory and each technique carries its own advantages and disadvantages to both patient and surgeon.

\section{CONCLUSION}

- Giant prosthetic reinforcement of the visceral sacStoppa's repair is a good alternative to Lichtenstein's repair for primary bilateral inguinal hernia.

- Giant prosthetic reinforcement of the visceral sac is far superior to Lichtenstein repair for recurrent inguinal hernia.

- Time taken to return to normal activity is more for Stoppa's repair and time taken to return to normal activity and chronic groin pain is more for Lichtenstein's hernia repair.

\section{ACKNOWLEDGEMENT}

- This work represents the combined effort of a large number of individuals and it is my pleasure to acknowledge those concerned without whom this work would have been impossible.

- I am extremely grateful to Dr. R. V. Ramlal, Associate Professor, Department of General Surgery, Govt. T. D. Medical College, Alappuzha for the support and invaluable suggestions provided at various stages of the study and for all the efforts in facilitating the smooth conduct of the study.

- I am extremely thankful to Dr. N. R. Sajikumar, Additional Professor, Department of General Surgery, Govt. T. D. Medical College, Alappuzha for his zealful and motivating words in conducting this study.
- I express my sincere thanks to Dr. P. Mohandas, Additional Professor, Department of General Surgery, Govt. T. D Medical College, Alappuzha for his valuable advice and support.

- I express my sincere thanks to Dr. Y. Shajahan, Additional Professor, Department of General Surgery, Govt. T. D. Medical College, Alappuzha for his valuable advice and support.

\section{REFERENCES}

[1] Anson BJ, Morgan EH, McVay CB. Surgical anatomy of the inguinal region based upon a study of 500 bodyhalves. Surg Gynecol Obstet 1960;111:707-25.

[2] Gilbert AI. An anatomic and functional classification for the diagnosis and treatment of inguinal hernia. Am J Surg 1989;157(3):331-3.

[3] Read RC, Barone GW, Hauei-Jensen M. Preperitoneal prosthetic placement through the groin. Surg Clin North Am 1993;73:545-55.

[4] Kux M. Anatomy of the groin: a view from the surgeon. In: Fitzgibbons RJ, Greenberg AG. eds. Nyhus and Condon's Hernia. $5^{\text {th }}$ edn. Philadelphia: Lippincolt Williams \& Wilkins 2002:45-53.

[5] Condon RE. The anatomy of the inguinal region and its relation to groin hernia. In: Nyhus LM, Harkins HN. eds. Hernia. $3^{\text {rd }}$ edn. Philadelphia: JB Lippincott 1989.

[6] Condon RE. The anatomy of the inguinal region and its relation to groin hernia. In: Nyhus LM, Harkins HN. eds. Hernia. $4^{\text {th }}$ edn. Philadelphia: JB Lippincott 1995.

[7] Lichtenstein IL, Shulman AG, Amid PK, et al. The tension free hernioplasty. Am J Surg 1989;157(2):188-93.

[8] Casten DF. Functional anatomy of the groin area as related to the classification and treatment of groin hernias. Am J Surg 1967;114(6):894-9.

[9] Bendavid R. The Space of Bogros and the deep inguinal venous circulation. Surg Gynaec Obstet 1992:174(5):355-8.

[10] Bendavid R. The Space of Retzius and the deep inguinal venous circulation. Surg Gynaec Obstet 1992:174-355. 